Tugas Mata Kuliah Program Doktor (S3) UNP PERANCANGAN SISTEM PEMBELAJARAN

Dosen Pembimbing:

Prof. Dr. Z. Mawardi Effendi, M.Pd

Dr. Jasrial, M.Pd

Materi:

KAJIAN DAN REFLEKSI MODEL

PEMBELAJARAN

Disajikan oleh:

Yofita Sandra_Dosen Seni Rupa_UNP 


\section{PENTINGNYA KAJIAN DAN \\ REFLEKSI MODEL PEMBELAJARAN}

- Kegiatan pendidik tidak optimal bila hanya mengenal satu model tertentu

- Setiap model memiliki sintaks yang berbeda

- Masing-masing model memiliki keunggulan dan keterbatasan 


\section{Ciri-ciri Model Pembelajaran}

a. Memiliki dasar yang kuat dari teori pendidikan dan teori belajar menurut para ahli tertentu,

b. memiliki misi atau tujuan pendidikan tertentu,

c. menjadi pedoman untuk perbaikan dan peningkatan proses pembelajan,

d. memiliki bagian-bagian yang disebut syntax, prinspprinsip reaksi, sistem sosial, dan sistem pendukung,

e. memiliki dampak pembelajaran dan dampak pengiring sebagai konsekuensi diterapkannya model tertentu, dan

f. pengajar membuat persiapan mengajar berdasarkan model yang dipilih tersebut (Rusman, 2012). 


\section{Jenis Model}

1. Model Desain Pembelajaran Konseptual (Conceptual Instructional Design Models)

a. Theory-driven conceptual Instructional Design Models. b. Practice-driven conceptual Instructional Design Models.

2. Model Desain Pembelajaran Prosedural (Procedural Instructional Design Models)

a. Theory-driven procedural Instructional Design Models. b. Practice-driven procedural Instructional Design Models. c. Hybrid procedural Instructional Design Models. 


\section{Refleksi}

- Refleksi adalah pencarian terdahap aturan atau prinsip-prinsip umum berdasarkan fakta yang sebagian besar disimpan dalam memori

- Refleksi juga merupakan pencarian terhadap kemungkinan jawaban pasti, pertanyaanpertanyaan baru, berikut fakta yang mendukung penemuan jawaban tersebut

(Glatthorn \& Baron, 1991) 


\section{Contoh Tindakan Refleksi Dalam}

\section{Pembelajaran}

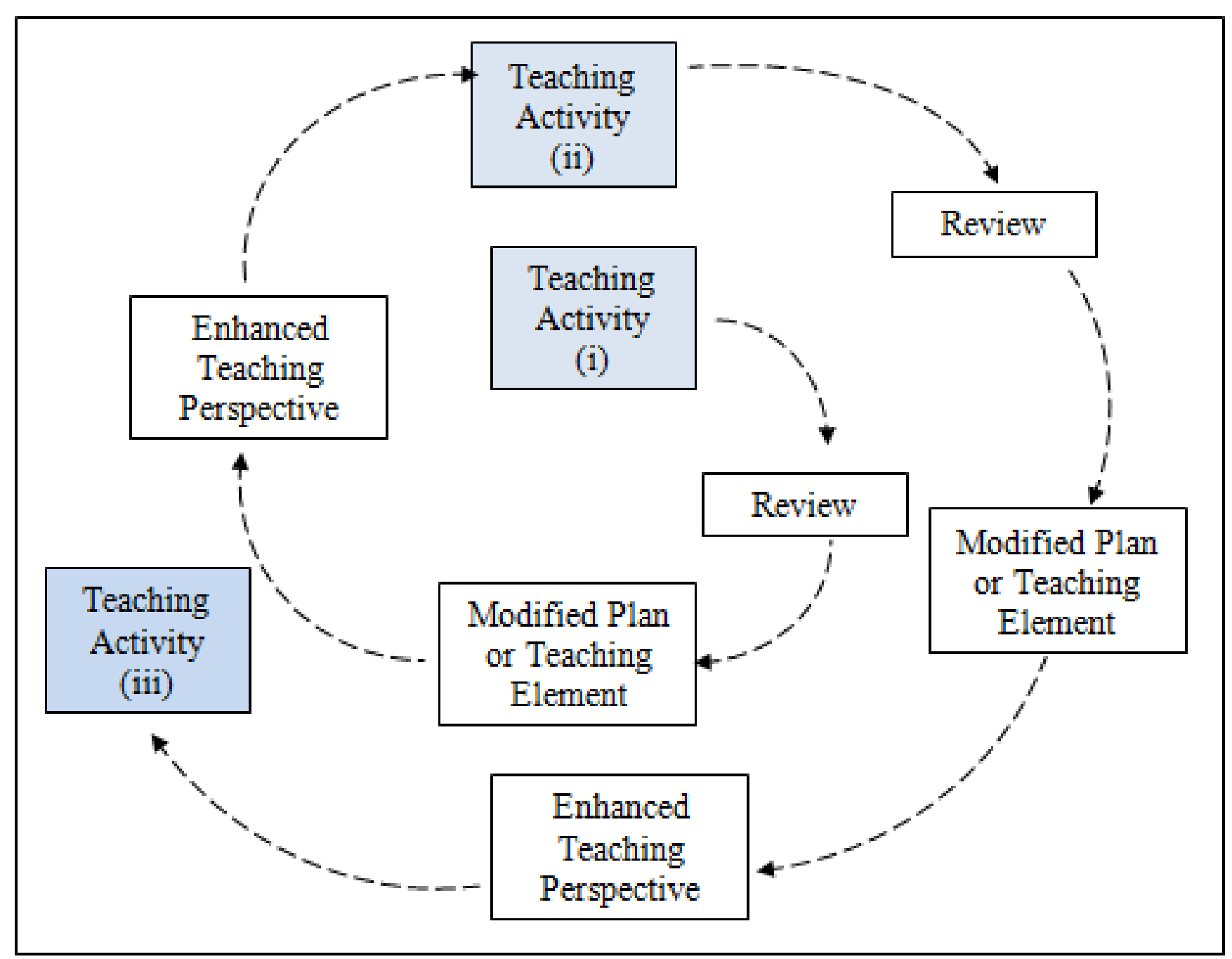

Sumber: (Rose, 2018) 


\section{Kaitan Model Pembelajaran dengan}

\section{Desain Sistem Pembelajaran}

- Smith dan Ragan (dalam Pribadi, 2010: 58) menyebutkan bahwa desain sistem pembelajaran adalah proses sistematik yang dilakukan dengan menerjemahkan prinsipprinsip belajar dan pembelajaran menjadi rancangan yang dapat diimplementasikan dalam bahan dan aktivitas pembelajaran. 
Teori-teori Pokok Yang Mendasari

Bidang Desain Sistem Pembelajaran

(1)Teori sistem,

(2)Teori komunikasi,

(3)Teori belajar, dan

(4)Teori pembelajaran. 


\section{Temuan tentang Beberapa Model Pembelajaran}

1. Model Interaksi Sosial

2. Model Pemrosesan Informasi

3. Model Personal

4. Model Modifikasi Tingkah Laku 


\section{Rumpun Model Interaksi Sosial}

\begin{tabular}{l|l|l|l|}
\hline No. & Model & Tujuan & Tokoh \\
\hline 1. & $\begin{array}{l}\text { Penentuan } \\
\text { Kelompok }\end{array}$ & $\begin{array}{l}\text { Dapat terlibat aktif dalam proses sosial demokratis } \\
\text { sebagai bentuk kombinasi keterampilan pribadi } \\
\text { (kelompok) dan keterampilan akademik. }\end{array}$ & $\begin{array}{l}\text { Herbert Telen \& John } \\
\text { Dewey. }\end{array}$ \\
\hline 2. & Inkuiri Sosial & Memecahkan masalah-masalah sosial & $\begin{array}{l}\text { Byron Massialas \& } \\
\text { Benjamin Cox }\end{array}$ \\
\hline 3. & $\begin{array}{l}\text { Metode } \\
\text { Laboratori }\end{array}$ & $\begin{array}{l}\text { Perkembangan keterampilan antara pribadi dan } \\
\text { kelompok }\end{array}$ & $\begin{array}{l}\text { Bethel Maine (National } \\
\text { Teaching Library) }\end{array}$ \\
\hline 4. & $\begin{array}{l}\text { Jurisprudensi } \\
\text { al }\end{array}$ & $\begin{array}{l}\text { Membangun kerangka acuan penyelesaian isu-isu } \\
\text { sosial }\end{array}$ & $\begin{array}{l}\text { Donald Oliver \& James P. } \\
\text { Shaver }\end{array}$ \\
\hline 5. & $\begin{array}{l}\text { Bermain } \\
\text { peran }\end{array}$ & $\begin{array}{l}\text { Mempengaruhi peserta didik menemukan nilai-nilai } \\
\text { pribadi dan sosial hingga menjadi sumber penemuan } \\
\text { pribadi dan sosial gemilang berikutnya. }\end{array}$ & $\begin{array}{l}\text { Fainnie Shatel \& George } \\
\text { Fhatel }\end{array}$ \\
\hline 6. & $\begin{array}{l}\text { Simulasi } \\
\text { Sosial }\end{array}$ & $\begin{array}{l}\text { Perolehan konsep pembuatan keputusan dari } \\
\text { serangkaian proses kenyataan sosial yang ditanggapi }\end{array}$ & $\begin{array}{l}\text { Sarene Bookock \& Harold } \\
\text { Guetzkov }\end{array}$ \\
\hline
\end{tabular}




\section{Rumpun Model Pemrosesan Informasi}

\begin{tabular}{|c|c|c|c|}
\hline No. & Model & Tujuan & Tokoh \\
\hline 1. & $\begin{array}{l}\text { Model } \\
\text { berpikir } \\
\text { induktif }\end{array}$ & $\begin{array}{l}\text { Mengembangkan proses mental induktif dan } \\
\text { penalaran akademik }\end{array}$ & Hilda Taba \\
\hline 2. & $\begin{array}{l}\text { Model } \\
\text { latihan } \\
\text { inkuiri }\end{array}$ & $\begin{array}{l}\text { Pemecahan masalah sosial melalui penemuan sosial } \\
\text { dan penalaran logis }\end{array}$ & Ricard Suchman \\
\hline 3. & $\begin{array}{l}\text { Inkuiri } \\
\text { ilmiah }\end{array}$ & $\begin{array}{l}\text { Untuk memudahkan mengajarkan sistem penelitan } \\
\text { menurut satu disiplin ilmu yang kemudian memiliki } \\
\text { dampak pada kawasan-kawasan lain }\end{array}$ & Joseph J. Schwab \\
\hline 4. & $\begin{array}{l}\text { Penemuan } \\
\text { Konsep }\end{array}$ & $\begin{array}{l}\text { Mengembangkan penalaran induktif sekaligus } \\
\text { analisis konsep }\end{array}$ & Jerome Bruner \\
\hline 5. & $\begin{array}{l}\text { Pertumbuhan } \\
\text { kognitif }\end{array}$ & Menemukan nilai-nilai pribadi dan sosial & $\begin{array}{l}\text { Jean Piaget } \\
\text { Irving Sigel } \\
\text { Edmund Sullivan } \\
\text { Lawrence Kolberg }\end{array}$ \\
\hline 6. & $\begin{array}{l}\text { Model } \\
\text { penata } \\
\text { lanjutan }\end{array}$ & $\begin{array}{l}\text { Meningkatkan efisiensi kemampuan pemrosesan } \\
\text { informasi }\end{array}$ & David Ausubel \\
\hline 7. & Memori & Meningkatkan kemampuan mengingat & $\begin{array}{l}\text { Harry Lorayne } \\
\text { Jerry Lucas }\end{array}$ \\
\hline
\end{tabular}




\section{Rumpun Model Personal}

\begin{tabular}{|l|l|l|l|}
\hline No. & Model & Tujuan & Tokoh \\
\hline 1. & $\begin{array}{l}\text { Pengajaran } \\
\text { non-direktif }\end{array}$ & $\begin{array}{l}\text { Pembentukan kemampuan untuk } \\
\text { mengembangkan diri, kesadaran diri, } \\
\text { pemahaman diri, kamandirian, konsep diri. }\end{array}$ & Carl Rogers \\
\hline 2. & $\begin{array}{l}\text { Latihan } \\
\text { kesadaran }\end{array}$ & $\begin{array}{l}\text { Meningkatkan kemampuan eksplorasi diri, } \\
\text { kesadaran diri. }\end{array}$ & $\begin{array}{l}\text { Fritz Perls } \\
\text { Willian Schultz }\end{array}$ \\
\hline 3. & Sinektik & $\begin{array}{l}\text { Mengembangkan pribadi dalam kreativitas } \\
\text { serta pemecahan masalah }\end{array}$ & William Gordon \\
\hline 4. & $\begin{array}{l}\text { Sistem- } \\
\text { sistem } \\
\text { Konseptual }\end{array}$ & $\begin{array}{l}\text { Meningkatkan kompleksitas dan keluwesan } \\
\text { diri }\end{array}$ & David Hunt \\
\hline 5. & $\begin{array}{l}\text { Pertemuan } \\
\text { kelas }\end{array}$ & $\begin{array}{l}\text { Meningkatkan pemahaman diri dan dan } \\
\text { tanggung jawab diri serta kelompok sosial }\end{array}$ & William Glasser \\
\hline
\end{tabular}




\section{Rumpun Model Modifikasi Tingkah Laku}

\begin{tabular}{|l|l|l|l|}
\hline No. & Model & Tujuan & Tokoh \\
\hline 1. & $\begin{array}{l}\text { Manajemen } \\
\text { Kontigensi }\end{array}$ & $\begin{array}{l}\text { Penanaman Pengajaran fakta-fakta, } \\
\text { konsep, keterampilan }\end{array}$ & B.F. Skinner \\
\hline 2. & Kontrol diri & $\begin{array}{l}\text { Pemantapan perolehan keterampilan } \\
\text { sosial }\end{array}$ & B.F. Skinner \\
\hline 3. & Relaksasi & $\begin{array}{l}\text { Tujuan pribadi untuk mengurangi } \\
\text { ketegangan atau kecemasan }\end{array}$ & $\begin{array}{l}\text { Rimm \& Masters } \\
\text { Wolpe }\end{array}$ \\
\hline 4. & $\begin{array}{l}\text { Pengurangan } \\
\text { Ketegangan }\end{array}$ & $\begin{array}{l}\text { Mengalihkan kesantaian kepada } \\
\text { kecemasan dalam situasi sosial }\end{array}$ & $\begin{array}{l}\text { Rimm \& Masters } \\
\text { Wolpe }\end{array}$ \\
\hline 5. & $\begin{array}{l}\text { Latihan } \\
\text { Asertif } \\
\text { Desensitisasi }\end{array}$ & $\begin{array}{l}\text { Peningkatan kemampaun } \\
\text { mengekspresikan perasaan secara } \\
\text { langsung dan spontan dalam situasi sosial }\end{array}$ & $\begin{array}{l}\text { Wolpe, Lazarus, } \\
\text { Salter }\end{array}$ \\
\hline 6. & $\begin{array}{l}\text { Latihan } \\
\text { Langsung }\end{array}$ & $\begin{array}{l}\text { Pembentukan pola-pola perilaku, } \\
\text { keterampilan }\end{array}$ & $\begin{array}{l}\text { Gagne, Smith \& } \\
\text { Smith }\end{array}$
\end{tabular}




\section{Model-model Desain Pembelajaran}

\begin{tabular}{|l|l|l|}
\hline No. & Model & Pengembang \\
\hline 1. & Model Desain Sistematik & $\begin{array}{l}\text { Walter Dick dan } \\
\text { Lou Carey }\end{array}$ \\
\hline 2. & Model ASSURE & $\begin{array}{l}\text { Sharon E. } \\
\text { Smaldino, James } \\
\text { D. Russel, Robert } \\
\text { Heinich, dan }\end{array}$ \\
& & $\begin{array}{l}\text { Michael Molenda } \\
\text { Jerold E. Kemp }\end{array}$ \\
\hline 3. & Model Cycle & A.W. Bates. \\
\hline 4. & $\begin{array}{l}\text { Model ADDIE dan Model } \\
\text { Desain Front-end Systematic } \\
\text { Design }\end{array}$ & \\
\hline
\end{tabular}




\section{Model Dick and Carey}

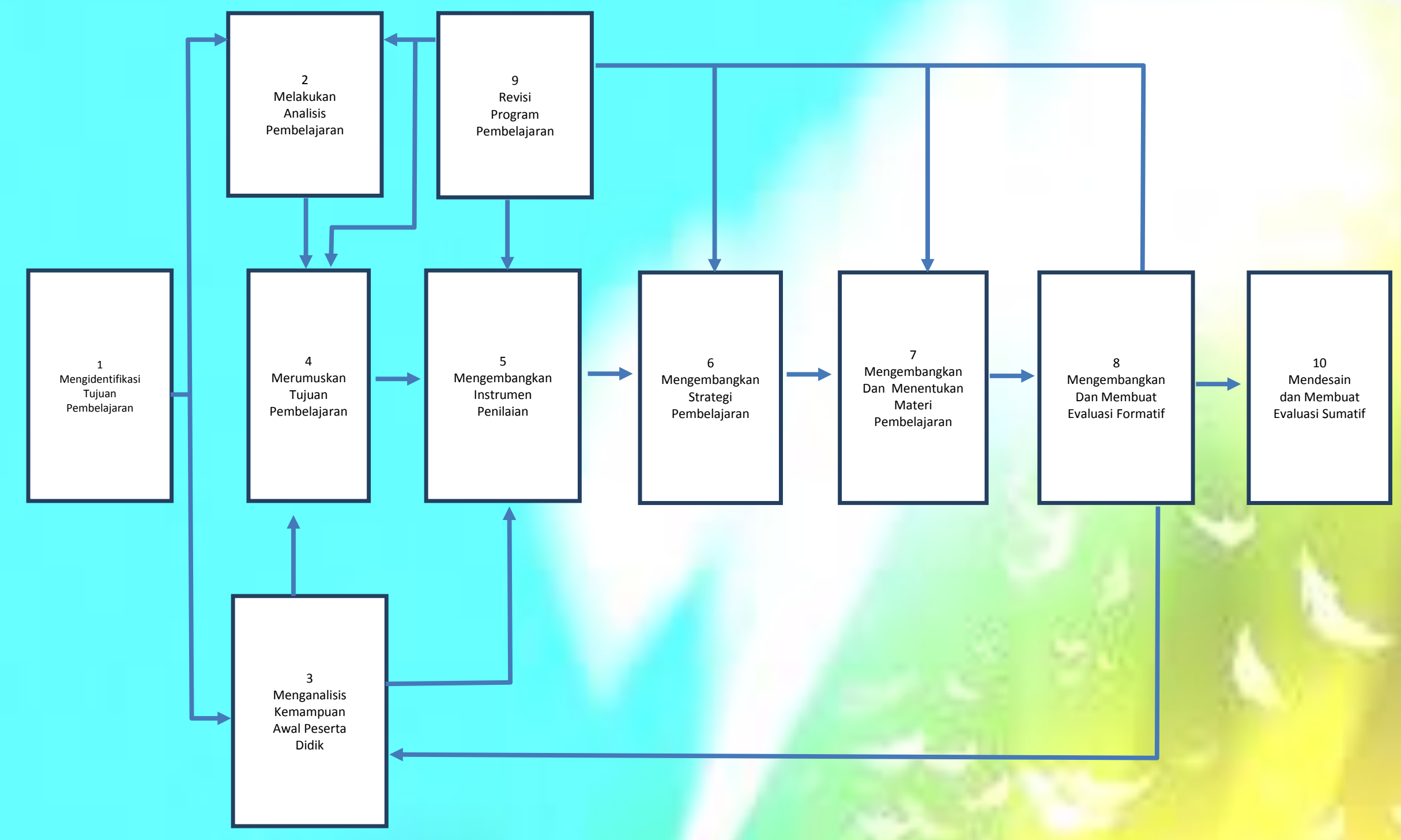


- Kelebihan: dapat dimanfaatkan dalam dunia bisnis, industri, pemerintahan dan pelatihan. Model ini juga berguna untuk menghasilkan pembelajaran berbasis komputer (computer assisted learning dan program multimedia). Pada tahap analisis dan evaluasi, model ini bersifat rinci dan komprehensif.

- Kekurangan: karena merupakan desain prosedural, pengembangannya terkesan kaku, desain harus matang, tidak ada uji coba kecuali setelah evaluasi formatif. Dan bila diselenggarakan dengan pembelajaran berbasis web, pendidik kesulitan mengidentifiksi karakter peserta didik. 


\section{Model ASSURE}

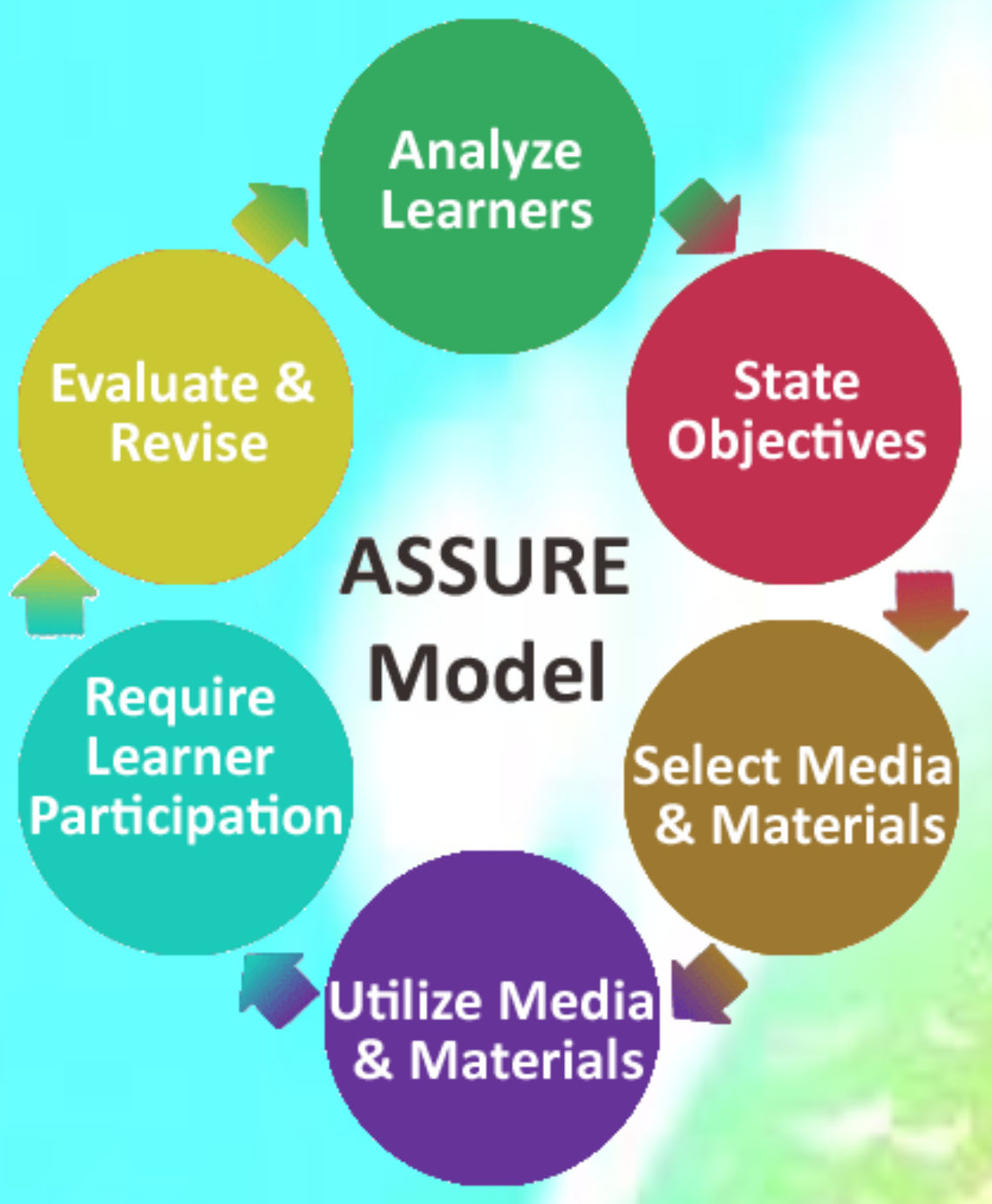


- Kelebihan: sederhana, relatif mudah untuk diterapkan, dapat dikembangkan sendiri oleh pengajar, komponen pembelajaran lengkap, dan peserta didik dapat dilibatkan dalam persiapan pembelajaran.

- Kekurangan: tidak mengukur dampat proses belajar karena tidak didukung suprasistem, tugas pendidik bertambah, harus ada upaya khusus dalam mengaktifkan peserta didik.. 


\section{Model Cycle}

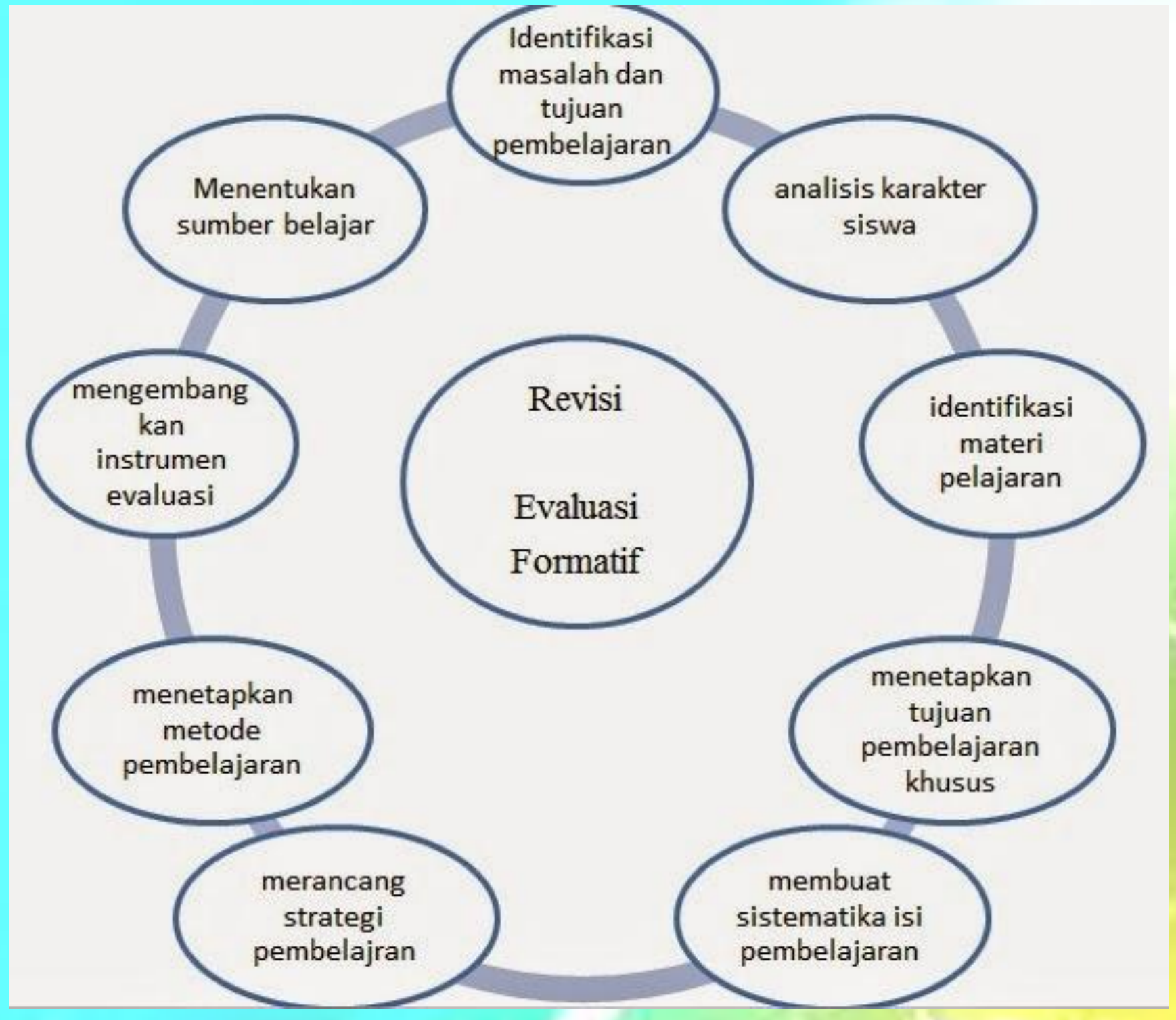


- Kelebihan: pendidik dapat melakukan pemantauan sebelum melangkah ke tahap berikut, jika ditemukakan kekurangan dapat dirombak dan diubah, jika dapat diatasi dapat langsung ke tahap selanjutnya.

- Kekurangan: hanya fokus pada perancangan pembelajaran kelas, guru berperan sentral, tuntutan pembuatan rangka program mengajar dan strategi tinggi. 


\section{Model ADDIE}

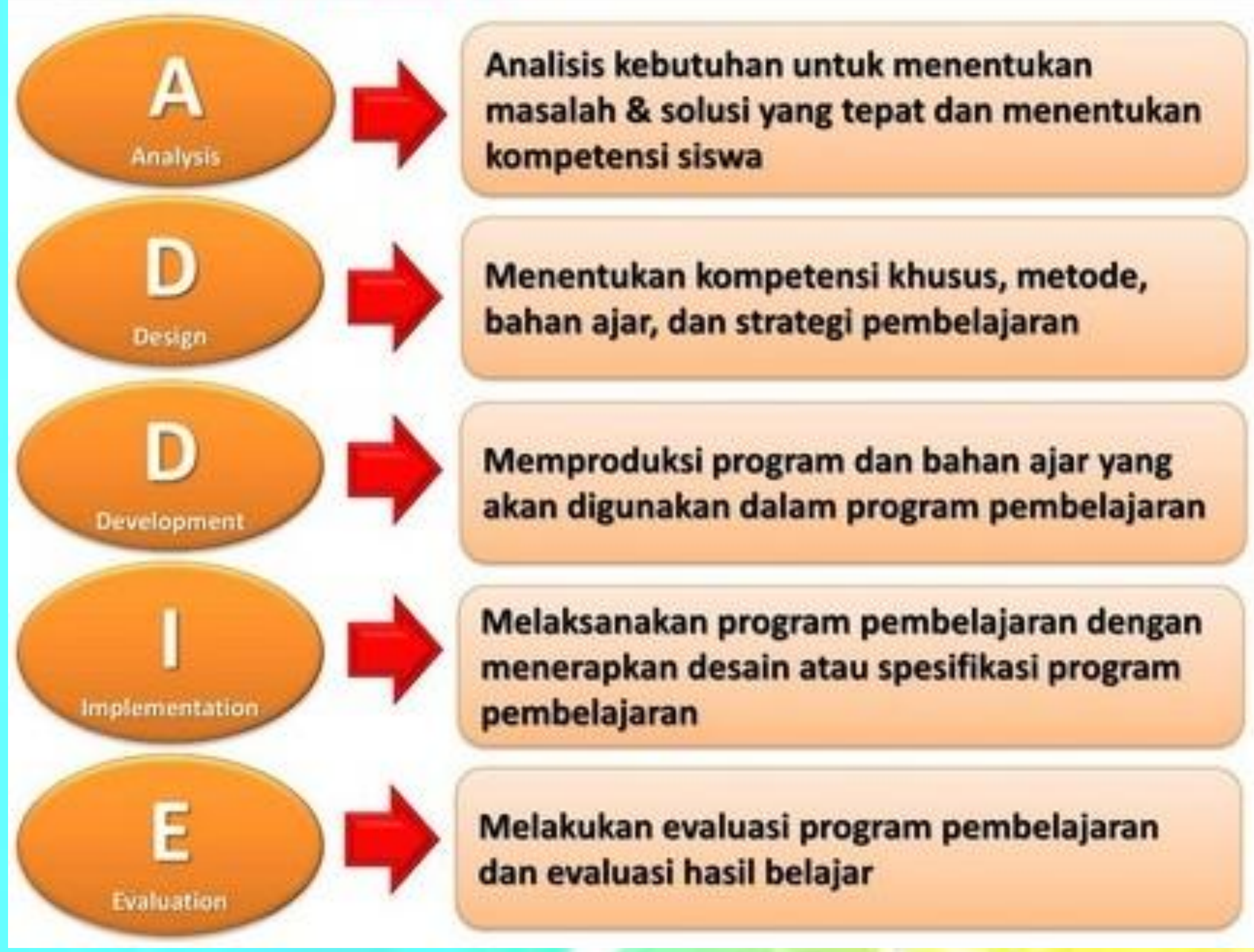


- Kelebihan: sederhana, mudah dipelajari dan struktunya sistematis..

- Kekurangan: dibutuhkan waktu yang cukup lama untuk melakukan tahap analisis.. 


\section{Aplikasi Model Pembelajaran yang}

\section{Sesuai dengan Kondisi}

- Banathy dalam Reigeluth (2009:390) identified for subsystem that can be viewed as levels of any educational system:

(1) the learning experience system,

(2) the instructional system recides,

(3) the administrative system recides, and

(4) government system recides. 


\section{Visi Sistem Pendidikan Era Informasi}

a. Customization and diversity

b. Initiative and self direction

c. Collaboration and emotional development

d. Holism and integration 